\title{
Article \\ What Predicts Korean Citizens' Mask-Wearing Behaviors? Health Beliefs and Protective Behaviors against Particulate Matter
}

\author{
Jarim Kim $^{1}$ and Yerim Kim $^{2, *(D)}$ \\ 1 Department of Communication, Yonsei University, Seoul 03722, Korea; jarimkim@yonsei.ac.kr \\ 2 Department of Neurology, Kangdong Sacred Heart Hospital, College of Medicine, Hallym University, \\ Seoul 05355, Korea \\ * Correspondence: brainyrk@hallym.ac.kr
}

check for

updates

Citation: Kim, J.; Kim, Y. What Predicts Korean Citizens'

Mask-Wearing Behaviors? Health

Beliefs and Protective Behaviors against Particulate Matter. Int. J. Environ. Res. Public Health 2021, 18, 2791. https://doi.org/10.3390/ ijerph18062791

Academic Editors: Helen Petach, Gila Neta and Matthew Freeman

Received: 10 February 2021

Accepted: 8 March 2021

Published: 10 March 2021

Publisher's Note: MDPI stays neutral with regard to jurisdictional claims in published maps and institutional affiliations.

Copyright: (c) 2021 by the authors. Licensee MDPI, Basel, Switzerland. This article is an open access article distributed under the terms and conditions of the Creative Commons Attribution (CC BY) license (https:// creativecommons.org/licenses/by/ $4.0 /$ )

\begin{abstract}
Air pollution has become a critically important contemporary issue, exposing people to various health risks worldwide. Air pollution problems cannot be resolved in the short-term; therefore, citizens in regions with low air quality are encouraged to take protective actions such as wearing masks to filter particulate matter. However, compliance with such recommendations is limited. To enhance the effectiveness of health promotion in this regard, this study applied the health belief model to examine the factors that affect mask-wearing behaviors. It also investigates the factors that influence particulate matter-related health beliefs and protective behaviors. A cross-sectional survey with 200 Korean citizens was conducted. The results revealed associations between masking behaviors and both perceived benefits of and perceived physical barriers to wearing masks. In addition, sex, education, income, and having heard of different particulate matter-related health consequences were found to predict mask-wearing. This study demonstrates the utility of the health belief model in the context of air pollution and has practical implications for health promotion practitioners.
\end{abstract}

Keywords: particulate matter; health belief model; perceived susceptibility; perceived severity; perceived benefits; perceived barriers; mask-wearing; health promotion; health communication

\section{Introduction}

Every year, more than four million people worldwide lose their lives prematurely due to heart disease, pneumonia, stroke, chronic obstructive pulmonary disease, and lung cancer caused by outdoor air pollution [1]. Approximately $92 \%$ of people worldwide live in environments where air quality levels do not meet standards set by the World Health Organization (WHO). The WHO set air quality guidelines as an annual mean of fine particulate matter of (PM) 2.5 of less than $10 \mu \mathrm{g} / \mathrm{m}^{3}$ [2]. Particle matter (PM), comprising small solid or liquid aerosols, is harmful when inhaled [3]. $\mathrm{PM}_{2.5}$, fine, inhalable particles that are 2.5 micrometers or smaller in diameter [4], are dangerous because they can penetrate more deeply into the body and reach the blood or lungs. PM exposure is linked to various health effects, ranging from eye irritation and breathing trouble to heart disease and lung cancer [5]. One study ranked $\mathrm{PM}_{2.5}$ fifth among 79 risk factors responsible for global diseases in 195 countries [6].

PM issues have emerged as a major concern in Korea. According to 2019 data concerning population exposure to $\mathrm{PM}_{2.5}$, Korea ranked highest among the Organization for Economic Cooperation and Development (OECD) countries at $27.5 \mu \mathrm{g} / \mathrm{m}^{3}$, almost doubling the average exposure of other OECD countries $\left(13.9 \mu \mathrm{g} / \mathrm{m}^{3}\right)$ and three-fold higher than the WHO standard $\left(10 \mu \mathrm{g} / \mathrm{m}^{3}\right)$ [7]. Recognizing the risk of such exposure posed to citizens, the Korean government enacted the Special Act on the Reduction and Management of Fine Dust on 14 August 2018 [8], implementing protective measures including 
notifying citizens of PM-related problems or the PM status in given locations. For example, in 2019, citizens in Seoul, the capital of Korea, received 41 "bad" day $\left(36-75 \mu \mathrm{g} / \mathrm{m}^{3}\right)$ and 9 "very bad" day (more than $76 \mu \mathrm{g} / \mathrm{m}^{3}$ ) warnings [9]. As protective actions, the government recommends that citizens refrain from outdoor activities and to wear masks certified by the Korean Centers for Disease Control and Prevention, such as N95, KF94, or KF80 types, when then need to go outside. However, for various reasons, including the discomfort or stifling feeling caused by wearing a mask or monetary cost for mask acquisition, some citizens do not comply with governmental guidelines [10], or use other types of masks that may not effectively filter out $\mathrm{PM}_{2.5}$ [11].

Considering that this air pollution issue cannot be resolved in a day or a year, it is important to theoretically understand why citizens do not comply with governmental recommendations and identify practical strategies to help them engage in protective actions to reduce the health risks they face. Most PM-related studies have taken more natural scientific or engineering approaches, focusing, for example, on mask-wearing's efficacy in reducing health risks [12,13], or the links between PM and different diseases [13,14]. Meanwhile, researchers have paid relatively little attention to the variables that influence individuals' protective behaviors-an area that urgently requires research in the short-term to reduce negative heath consequences. Thus, guided by the health belief model [15] (acknowledged as one of the most useful frameworks for explaining health behaviors [16]), this study examines the factors that affect mask-wearing behaviors.

\section{Theoretical Framework}

\subsection{Health Belief Model}

The health belief model (HBM) was developed in the 1950s to understand why U.S. citizens did not participate in disease prevention programs. It has guided various health behavior interventions by providing a framework for investigating the various health beliefs associated with different health-related issues $[17,18]$, and a considerable number of empirical studies have supported its theoretical and practical utility [19]. Based on the value-expectancy approach, which predicts human behaviors based on one's evaluation of an outcome and expectation that one's behavior will result in that outcome [20], the theory postulated that individuals value avoiding diseases and expect that their specific health behaviors will prevent diseases [21].

The HBM comprises the following four basic constructs: (i) perceived susceptibility, which refers to the perceived likelihood of a risk's occurrence; (ii) perceived severity, which refers to the perceived seriousness of a risk's consequences; (iii) perceived benefits, which refers to the perceived efficacy of a behavior in reducing a risk; and (iv) perceived barriers, which refers to the perceived psychological, physical, financial, and other costs of engaging in a particular behavior [20,21]. Higher levels of perceived susceptibility and perceived severity have been shown to increase the perceived threat posed by a given risk, whereas higher levels of perceived benefits and lower levels of perceived barriers increase the likelihood of engaging in suggested health behaviors [22]. The theory has been applied to various health contexts, including breast cancer screening [23], condom use [24], H1N1 vaccination [25], HPV vaccination [26], exercising [27], energy drink consumption [28], and smoking [29].

Earlier review studies [30,31] have identified perceived barriers as the strongest predictor and perceived severity as the weakest predictor across different health behaviors. Janz and Becker also found that the associations between health beliefs and behaviors differed depending on the type of health behaviors. Specifically, they found that perceived susceptibility better predicts preventative behaviors, whereas perceived severity and benefits better predict treatment behaviors of already diagnosed diseases. Perceived barriers did not differ across types. However, a more recent meta-analysis focusing only on longitudinal studies [32] identified perceived benefits and barriers as the strongest predictors and perceived severity as a weak predictor. This same study found that perceived susceptibility had almost null associations with health behaviors. In short, findings regarding 
the strength of the associations between different health beliefs and health behaviors have been inconsistent, and these associations therefore require further research [32,33]. Based on this theoretical framework, the current study examined the effects of health beliefs on protective behaviors against PM-mask-wearing-and the potential antecedents that may affect health beliefs about mask-wearing. Despite its utility in various health contexts, the HBM has rarely, if ever, been utilized to examine individuals' protective behaviors against air pollution.

This study postulates that mask-wearing behaviors are associated with health beliefs, including the perceived susceptibility to PM-related diseases, perceived severity of PM-related health consequences, perceived benefits of wearing masks in reducing PM-related risks, and perceived barriers to mask-wearing. Most prior studies have regarded perceived barriers as a unidimensional factor, agglomerating different types of barriers including physical, psychological, financial, and other costs [25,34,35]. More recent studies $[26,28,36,37]$, however, have emphasized the multidimensional nature of this concept. Following prior research regarding protective behaviors [26,37], this study distinguishes between the physical and financial/logistical barriers to wearing masks. Although no prior studies have directly examined the relationships between PM-related health beliefs and protective behaviors, based on the extant HBM research, this study posits the following hypotheses (Hs):

Hypothesis 1 (H1). Perceived susceptibility to PM-related diseases positively predicts maskwearing behaviors.

Hypothesis 2 (H2). Perceived severity of PM-related health consequences positively predicts mask-wearing behaviors.

Hypothesis 3 (H3). Perceived benefits of wearing masks positively predict mask-wearing behaviors.

Hypothesis 4 (H4). Perceived physical barriers to wearing masks negatively predict mask-wearing behaviors.

Hypothesis 5 (H5). Perceived financial/logistical barriers in wearing masks negatively predict mask-wearing behaviors.

\subsection{Predictors of PM-Related Health Beleifs and Protective Behavios against PM}

Moreover, this study takes into consideration the diverse sociodemographic characteristics that may affect individuals' health beliefs and behaviors. The original HBM assumed such relationships [31], but prior studies have neglected them. Although basic, engaging in effective communication requires an understanding of how different segments of the population grouped by sociodemographic characteristics demonstrate different health beliefs and behaviors. For example, younger people may perceive themselves as less likely to develop PM-related disease than older people, or women may find wearing masks less appealing because of how masks look on their faces. Such associations, if supported, mean that different communication messages need to be designed depending on group characteristics. Furthermore, clarifying such relationships will help determine which approaches are necessary to encourage citizens' mask-wearing. For example, if low-income predicts noncompliance with mask-wearing, policy- or community-level solutions to help low-income individuals acquire and wear masks may be more appropriate than persuading individuals to wear masks.

In line with this, the current study also explores how having heard of PM's diverse harmful consequences influences PM-related health beliefs and mask-wearing behaviors. People usually associate PM with certain respiratory diseases such as coughs or sore throats, not acknowledging its links to various serious ailments such as cardiovascular diseases or lung cancer. It is possible that simply having heard of or having communicated with others 
about different health consequences may affect individuals' health beliefs and resulting behaviors. Thus, the following research questions (RQs) are asked:

RQ1. Will any of the sociodemographic characteristics and having heard of PM's harmful health effects impact PM-related health beliefs?

RQ2. Will any of the sociodemographic characteristics and having heard of PM's harmful health effects impact mask-wearing behaviors?

\section{Materials and Methods}

\subsection{Subjects and Procedures}

A cross-sectional online survey was conducted with Korean adults between January 30, 2020, and February 3, 2020. Previous HBM research [32,33] has shown small to medium effects. A G*Power analysis [38] indicated that a total sample size of 138 would provide $95 \%$ power to detect a medium-sized effect $(f=0.15)$ in a multiple regression. Thus, we aimed to recruit at least 150 participants to achieve the requisite power. Subjects were recruited from a survey company EMBRAIN panel that consisted of 1.2 million Koreans. Based on stratified random sampling that represented the characteristics of Koreans in terms of age, sex, and region, a study invitation was sent to 4125 people; 282 completed the survey, and 82 were excluded due to sloppy responses and insufficient participation time, resulting in a final sample size of 200. It took subjects an average of $19.3 \mathrm{~min}$ to complete the survey and they were rewarded with EMBRAIN panel points, which can be exchanged for gifts or cash. The study received institutional review board approval before administering the survey and the researchers complied with ethical standards throughout the research.

\subsection{Measurements}

HBM measures were adapted from prior studies [26,37]. Three items were used to measure each of the HBM constructs including perceived susceptibility to PM-related diseases (e.g., "It is likely that I will get cancer or respiratory or cardiovascular diseases due to $\mathrm{PM}^{\prime}$ ), perceived severity of PM-related health consequences (e.g., "I believe that the PM will cause severe health problems"), and perceived benefits of wearing masks (e.g., "I believe wearing masks is effective in preventing cancer or the respiratory or cardiovascular diseases caused by $\left.\mathrm{PM}^{\prime \prime}\right)$. Perceived barriers to wearing masks were measured with two constructs adapted from prior research [26,37], including perceived physical barriers (e.g., "Wearing masks makes it hard for me to breathe") and perceived financial/logistical barriers (e.g., "I cannot afford masks", "I do not wear masks because of how silly they look"). Subjects were asked to respond on a 7-point Likert scale ranging from 1 (strongly disagree) to 7 (strongly agree), which were averaged to form an index for each construct.

To measure mask-wearing behaviors, subjects were asked "How many days did you wear masks in the past 30 days?" and "How many days did you wear masks in the past 3 months?" Air quality indexes for the past three months were presented with these questions as follows: "In the past three months, the fine dust index indicates 15 bad days, 60 average days, and 16 good days, while the ultra-fine dust index indicates 18 bad days, 53 average days, and 21 good days."

To measure the extent to which subjects had heard of PM-related negative health consequences, five questions concerning various health consequences were asked. Sample questions included: "Have you heard that the harmful health effects of PM can include lung cancer?" and "Have you heard that the harmful health effects of PM can include cardiovascular disease that can cause heart attack or stroke?" Subjects responded either 0 (no) or 1 (yes) to each question and the scores were added to form an index. In addition, sociodemographic information including age, sex, having children, education level, and annual income was collected. 


\subsection{Statistical Analysis}

To answer the research questions and test the hypotheses, a series of multiple regression analyses were conducted using SPSS Statistics 26 software (IBM Inc., Chicago, IL, USA). To control for the effects of sociodemographic characteristics or having heard of PM's harmful effects in examining the relationships between mask-wearing and health beliefs, data for the RQs were analyzed before those for the Hs. The severity of air pollution might differ based on the specific regions in which participants resided. Thus, region was controlled throughout the analyses. Specifically, for RQ1, each of the five health beliefs were included as dependent variables and sociodemographic characteristics (i.e., age, sex, having children, education, and income) and the extent to which individuals had heard of PM-related negative health effects were the independent variables. As with the RQ1 analyses, for RQ2, a series of regression analyses were performed with mask-wearing behaviors as the dependent variables and sociodemographic characteristics and the extent to which individuals had heard of PM-related negative health effects as the independent variables.

For H1, five health beliefs were included as independent variables, and mask-wearing behaviors in the past 30 days and in the past 3 months were the dependent variables for each analysis. Sex and having heard of PM's negative health consequences were included as covariates for the $\mathrm{H} 1$ test. To validate the dimension of health beliefs, a confirmatory factor analysis (CFA) was conducted using AMOS Graphics (SPSS software).

\section{Results}

\subsection{Descriptive Statistics and Dimensionality}

Table 1 presents descriptive statistics including sociodemographic characteristics. To validate the dimensionality of the five health belief dimensions including perceived susceptibility, perceived severity, perceived benefits, perceived physical barriers, and perceived logistical/financial barriers, a confirmatory factor analysis was conducted. The analysis yielded a very good model fit: $\chi^{2}(81)=133.78$, root mean square error of approximation $($ RMSEA $)=0.057$, comparative fit index $(\mathrm{CFI})=0.976$, Tucker-Lewis Index $(\mathrm{TLI})=0.969$. An RMSEA smaller than 0.06 and a CFI and a TLI larger than 0.90 and 0.95 , respectively, are suggested benchmarks for a good fit.

Table 1. Descriptive statistics.

\begin{tabular}{|c|c|c|c|}
\hline Variables $(n=200)$ & Levels & Frequency & Percentage \\
\hline \multirow[t]{2}{*}{ Sex } & Male & 98 & $49 \%$ \\
\hline & Female & 102 & $51 \%$ \\
\hline \multirow[t]{2}{*}{ Having children } & No & 83 & $41.5 \%$ \\
\hline & Yes & 117 & $58.5 \%$ \\
\hline \multirow[t]{5}{*}{ Education } & Less than high school & 2 & $1.0 \%$ \\
\hline & High school diploma & 25 & $12.5 \%$ \\
\hline & Some college & 30 & $15 \%$ \\
\hline & Bachelor's degree & 108 & $54 \%$ \\
\hline & Postgraduate degree and above & 35 & $17.5 \%$ \\
\hline \multirow[t]{8}{*}{ Annual income } & Less than $\$ 20,000$ & 30 & $15 \%$ \\
\hline & $\$ 20,000-30,000$ & 39 & $19.5 \%$ \\
\hline & $\$ 30,000-40,000$ & 39 & $19.5 \%$ \\
\hline & $\$ 40,000-50,000$ & 30 & $15 \%$ \\
\hline & $\$ 50,000-60,000$ & 22 & $11 \%$ \\
\hline & $\$ 60,000-70,000$ & 13 & $6.5 \%$ \\
\hline & $\$ 70,000-80,000$ & 9 & $4.5 \%$ \\
\hline & More than USD 80,000 & 18 & $9 \%$ \\
\hline
\end{tabular}


Table 1. Cont.

\begin{tabular}{cccc}
\hline Variables $(\boldsymbol{n}=\mathbf{2 0 0})$ & Levels & Frequency & Percentage \\
\hline Age & Cronbach's alpha & $\boldsymbol{M}$ & $\boldsymbol{S} \boldsymbol{D}$ \\
\hline MW for the past 30 days & & 44.04 & 13.27 \\
MW the past 3 months & & 8.38 & 8.36 \\
HHH & & 19.10 & 20.20 \\
Perceived susceptibility & 0.93 & 4.51 & 0.87 \\
Perceived severity & 0.93 & 4.92 & 1.23 \\
Perceived benefits & 0.93 & 5.60 & 1.03 \\
Perceived physical barriers & 0.88 & 5.15 & 0.94 \\
Perceived financial/logistical barriers & 0.73 & 5.53 & 0.93 \\
\end{tabular}

Note. M: mean; SD: standard deviation; MW: mask-wearing; and HHH: having heard of harmful health consequences.

\subsection{Main Results}

RQ1 asked if any of the sociodemographic characteristics and having heard of PM's negative health consequences were associated with PM-related health beliefs. As shown in Table 2, the analysis indicated that females were more likely to perceive PM-related consequences as more severe. Education and having heard of negative PM-related health consequences were also shown to have positive relationships with perceived susceptibility to and severity of PR-related consequences. Income, on the other hand, showed a negative relationship with perceived physical barriers to mask-wearing.

Table 2. Predictors of PM-related health beliefs and mask-wearing behaviors.

\begin{tabular}{|c|c|c|c|c|c|c|c|}
\hline $\begin{array}{l}\text { Predicting } \\
\text { Variables }\end{array}$ & $\begin{array}{c}\text { Perceived } \\
\text { Susceptibility }\end{array}$ & $\begin{array}{l}\text { Perceived } \\
\text { Severity }\end{array}$ & $\begin{array}{l}\text { Perceived } \\
\text { Benefits }\end{array}$ & $\begin{array}{c}\text { Perceived } \\
\text { Physical } \\
\text { Barriers }\end{array}$ & $\begin{array}{c}\text { Perceived } \\
\text { Logistical/ } \\
\text { Financial Barriers }\end{array}$ & $\begin{array}{l}\text { MW for the } \\
\text { Past } 30 \text { Days }\end{array}$ & $\begin{array}{c}\text { MW for the } \\
\text { Past } 3 \text { Months }\end{array}$ \\
\hline Sex & 0.021 & $0.164 *$ & -0.028 & 0.001 & -0.018 & $0.196^{* *}$ & $0.179 *$ \\
\hline Age & 0.000 & 0.015 & 0.000 & -0.101 & -0.003 & -0.150 & -0.122 \\
\hline $\mathrm{HC}$ & -0.039 & 0.004 & -0.093 & 0.097 & -0.044 & -0.037 & -0.070 \\
\hline Education & 0.180 * & $0.176^{*}$ & 0.023 & 0.089 & 0.096 & -0.077 & -0.040 \\
\hline Income & -0.110 & -0.035 & -0.009 & $-0.219 * *$ & -0.009 & $0.123^{+}$ & 0.113 \\
\hline $\mathrm{HHH}$ & $0.193^{* *}$ & $0.245^{* * *}$ & 0.118 & 0.103 & 0.043 & 0.155 * & 0.151 * \\
\hline Region & -0.039 & 0.040 & 0.008 & -0.089 & -0.002 & -0.016 & -0.003 \\
\hline Total $R^{2}$ & $0.078^{*}$ & $0.114^{* * *}$ & 0.024 & 0.060 & 0.014 & $0.102^{* *}$ & $0.087^{* *}$ \\
\hline Adjusted $R^{2}$ & $0.045^{*}$ & $0.082^{* * *}$ & -0.012 & 0.026 & -0.022 & $0.069^{* *}$ & $0.053 * *$ \\
\hline
\end{tabular}

Note. Numbers are standardized regression coefficients. HC: having children; MW: mask-wearing; and HHH: having heard of harmful health consequences; Sex: male $=1$, female $=2$; Having children: no $=0$, yes $=1$; Education: less than high school $=1$, high school diploma $=2$, some college $=3$, Bachelor's degree $=4$, postgraduate degree or above $=5$; Annual Income: below KRW 24 million (i.e., approx. below $\$ 20,000)=1$, KRW 24-36 million (i.e., approx. $\$ 20,000-30,000)=2$, KRW 36-48 million (i.e., approx. $\$ 30,000-40,000)=3$, KRW 48-60 million (i.e., approx. \$40,000-50,000) =4, KRW 60-72 million (i.e., approx. $\$ 50,000-60,000)=5$, KRW 72-84 million (i.e., approx. $\$ 60,000-70,000)=6$, KRW 84-96 million (i.e., approx. $\$ 70,000-80,000)=7$, KRW 96 million and above (i.e., approx. $\$ 80,000$ and above) = 8; Region: Seoul = 1, Pusan = 2, Daegu = 3, Incheon = 4, Gwangju = 5, Daejeon =6, Ulsan = 7; Having heard of PM-related negative health effects: higher scores indicate greater levels of having heard of different negative health effects. Significance indicated by ${ }^{\dagger} p<0.10$, ${ }^{*} p<0.05,{ }^{* *} p<0.01,{ }^{* * *} p<0.001$.

RQ2 asked if any of the sociodemographic characteristics and having heard of PM's harmful health consequences were associated with mask-wearing behaviors. As shown in Table 2, the analysis showed that females were more likely to have worn masks in the past 30 days as well as past 3 months. Having heard of different negative PM-related health consequences was also found to be positively associated with mask-wearing behaviors, both for the past month and the past 3 months.

H1-5 posited that health beliefs predict mask-wearing behaviors. Sex and having heard of negative health consequences caused by PM were related with mask-wearing behaviors; therefore, these two variables were included as covariates during analyses. As shown in Table 3, the perceived benefits of wearing masks were positively associated with mask-wearing for the preceding one and three months, and perceived physical barriers 
were negatively associated with mask-wearing for the previous one and three months, supporting H3 and H4. Meanwhile, no associations were found between mask-wearing behaviors and perceived susceptibility, perceived severity, and perceived financial/logistical barriers. Thus, H1, H2, and H5 were rejected.

Table 3. Predictors of mask-wearing behaviors.

\begin{tabular}{ccc}
\hline Predicting Variables & Past 30 Days & Past 3 Months \\
\hline Sex & $0.211^{* *}$ & $0.184^{* *}$ \\
Having heard of negative effects & $0.131^{\dagger}$ & 0.107 \\
Region & -0.042 & -0.031 \\
\hline Perceived susceptibility & 0.134 & 0.138 \\
Perceived severity & -0.035 & 0.009 \\
Perceived benefits & $0.196^{* *}$ & $0.238^{* * *}$ \\
Perceived physical barriers & $-0.256^{* * *}$ & $-0.192^{* *}$ \\
Perceived financial/logistic barriers & -0.013 & -0.034 \\
\hline Total $R^{2}$ & $0.174^{* * *}$ & $0.175^{* * *}$ \\
\hline Adjusted $R^{2}$ & $0.140^{* * *}$ & $0.141^{* * *}$
\end{tabular}

Note. Numbers are standardized regression coefficients. Sex: male $=1$, female $=2$; Having heard of PM-related negative health effects: higher scores indicate greater levels of having heard of different negative health effects; Region: Seoul $=1$, Pusan $=2$, Daegu $=3$, Incheon $=4$, Gwangju $=5$, Daejeon $=6$, Ulsan $=7$. Significance indicated by ${ }^{\dagger} p<0.10,{ }^{*} p<0.05,{ }^{* *} p<0.01, * * * p<0.001$.

\section{Discussion}

This study examined how people's health beliefs influence their mask-wearing behaviors to protect themselves from PM and whether sociodemographic characteristics and having heard of PM's harmful health consequences affect health beliefs and protective behaviors. The analysis showed that perceived benefits of wearing masks in reducing PM-related risks and perceived physical barriers to mask-wearing predict mask-wearing behaviors. It also showed that sex, education, income, and having heard of harmful effects predict health beliefs and mask-wearing behaviors.

The current study demonstrates the utility of HBM in predicting mask-wearing behaviors. Perceived benefits of and perceived physical barriers to wearing masks increased the likelihood of mask-wearing, but perceived susceptibility to PM-related diseases and perceived severity of PM-related health consequences did not, confirming the findings of an HBM meta-analysis [32], but undermining the argument of an earlier review [31] which perceived that susceptibility effectively predicts preventative behaviors. The findings of this study run counter to speculative assertions made in other previous studies as well [31,33]. These meta-analyses expected the predictive power of perceived severity to be weak based on the rationale that most individuals would perceive diseases such as AIDS or breast cancer as extremely severe. They predicted that this lack of variance between individuals would lead to small effect sizes. The variance in perceived severity in the current study, however, was even larger than the variance in other beliefs that showed statistically significant associations with behaviors, disconfirming such speculation.

One potential explanation for the null associations between mask-wearing and perceived severity and susceptibility is the uncertainty surrounding PM-related diseases. PM exposure has been linked to a number of potential health consequences, including cardiovascular and respiratory diseases, rather than a single concrete disease, and these diseases differ in seriousness (e.g., lung cancer vs. cough). Unlike some other health behaviors that prevent certain diseases, such as HPV vaccination preventing $70 \%$ of cervical cancer, the severity of PM-related consequences and individuals' susceptibility to them may not be certain. The fact that the findings of prior studies regarding the associations between health behaviors and perceived susceptibility and severity have not been consistent [31,32,39] highlights the need to examine (un)certainty regarding the risks posed in study contexts as a potential moderator.

On the other hand, this study found that perceived benefits and barriers predict maskwearing, supporting prior studies $[25,26,28,31,32,37]$ that have emphasized the importance 
of perceived benefits and barriers in predicting health behaviors. Perceived threats posed by susceptibility and severity may play some role in motivating action, but perceived benefits and barriers are the direct motivators that trigger health behaviors, demonstrating stronger associations across studies.

The findings of this study also revealed the multidimensionality of perceived barriers and their differential effects on health behaviors. Unlike the most extant studies, which have treated perceived barriers as unidimensional [25,34,35], this study made distinctions between physical barriers stemming from wearing masks and other barriers related to monetary costs or the logistics of wearing masks. The findings showed that only physical barriers predicted behaviors, implying that fully understanding health behaviors will require examination of different barriers. The findings also support prior studies that revealed different dimensions of perceived barriers $[26,28,37]$. The fact that studies have consistently found a close relationship between perceived barriers and health behaviors [32] emphasizes the critical importance of identifying context-specific barriers that need to be removed to promote health behaviors. For example, in the current context, removing physical barriers is important to increasing mask-wearing.

The current findings need to be interpreted in the Korean context. For example, the findings revealed that logistical/financial barriers are not big issues for Koreans. However, at the time, Koreans had experienced serious air pollution issues for several years, been exposed to media coverage highlighting the issue's seriousness, and became familiar with purchasing and wearing masks; these factors may explain this finding. Thus, logisti$\mathrm{cal} /$ financial barriers may prove more serious in other countries and deter citizens there from engaging in protective behaviors. For example, wearing masks may be viewed as culturally unacceptable in other cultures, or certified masks may cost much more, increasing related barriers. Additional research in this regard is therefore warranted.

Notably, this study found that a number of sociodemographic characteristics predict different health beliefs and mask-wearing behaviors. Specifically, females perceived PMrelated diseases as more severe, which made them more likely than males to wear masks. Those with higher levels of education perceived PM-related consequences as more severe and perceived themselves as more susceptible. Research has consistently shown a positive relationship between education and knowledge, because education enhances the skills necessary to learn and integrate necessary information [40-43]. The fact that PM-related knowledge is more accessible to those with higher education levels explains their higher levels of perceived susceptibility and severity. Interestingly, income was negatively associated with perceived physical barriers. The stuffiness or discomfort caused by wearing masks did not differ based on income levels. A possible rationale for this is that lower income-level jobs involve more outdoor work and therefore the workers in these jobs have to wear masks longer than their higher-earning counterparts. Additionally, such lower income jobs may involve more strenuous physical work, which may cause workers in these jobs to feel breathing difficulties caused by masks more acutely during work.

The current study also found that having heard of PM's diverse negative health consequences increased the levels of perceived susceptibility, perceived severity, and protective behaviors. Simply having heard about a given disease increased perceived risk levels and affected actual behaviors. This finding highlights the importance of communication. Exposure to simple information via different sources such as doctors, mass media, or social media can make people more aware of the given risks and lead them to engage in protective behaviors.

\subsection{Practical Implications}

The findings of this study have implications for health communication practitioners working in the air pollution context. Firstly, health communication practitioners need to design their key messages to highlight the perceived benefits of wearing masks and reducing perceived physical barriers. Although breathing can be uncomfortable with a mask on, people's physical discomfort may be based on preconceptions to some extent. In 
particular, one-fourth of the subjects in this study had not worn masks in the preceding 30 days, and $23 \%$ had not during the preceding 3 months. Helping them first experience mask-wearing would be another way to promote protective behaviors. In line with this, masks that make breathing more comfortable are currently being produced. Providing information regarding such options should also increase individuals' protective behaviors.

Secondly, practitioners need to develop different target-specific messages. For example, males perceived PM as less severe, and they were less likely to wear masks. Thus, mask-wearing promotions should target males and endeavor to increase their perceived severity. Majority-male workplaces or boys' schools could be good places to practice such promotions.

Thirdly, practitioners should work to inform citizens about PM's diverse negative health consequences. This study found that education and simply having heard of PM's negative health consequences were associated with perceived susceptibility and severity, revealing the need for awareness campaigns. This could be an opportunity for practitioners because it is more cost-effective than other communication efforts such as those seeking to change tobacco addiction-related behaviors, where motivating behavioral change is particularly difficult because people tend to maintain such behaviors even though they know about their negative consequences.

\subsection{Limitations and Future Research Directions}

Several limitations warrant mentions. Firstly, this study employed a retrospective design. Although two behavioral questions (i.e., 30 days, 3 months) were asked and participants' responses were consistent across them, their recollections of the numbers of times they had worn masks may not have been accurate. Future studies should consider different approaches such as having participants keep diaries over three months so as to monitor mask-wearing behaviors using panel data. In line with this, the participants were rewarded for their participation, which may have elicited biases in sample selection or responses (e.g., socially desirable responses). Future studies also need to consider more naturalistic designs that allow researchers to observe individuals' beliefs and behaviors.

Secondly, this study was conducted in Korea. Perceptions concerning mask-wearing differ across countries and cultures [44]. To enhance the generalizability and practical utility of this study's findings, researchers should endeavor to replicate it in locations with different cultural backgrounds. In areas with different cultural backgrounds, different health beliefs or sociodemographic characteristics may predict mask-wearing behaviors.

Lastly, the current study reflected citizens' perceptions and behaviors before the COVID-19 pandemic. COVID-19 has made use of masks a compulsory social norm. How such cultural shifts in mask usage will affect protective behaviors against PM pollution remains unclear. Citizens may have become more familiar with wearing masks and regard it as less bothersome. Alternatively, they may perceive wearing masks to protect against PM as less compulsory and important compared to COVID-19 and therefore enjoy the freedom of non-wearing. Air pollution will still be an issue even after the current pandemic ends, and understanding how and why citizens' protective behaviors change remains crucial.

\section{Conclusions}

This study investigated how different health beliefs regarding PM affect citizens' protective behaviors, and what variables influence PM-related beliefs and protective behaviors. This study found that the perceived benefits of and physical barriers to wearing masks predict protective mask-wearing behaviors. Additionally, it revealed that sex, education, income, and having heard of PM's harmful effects predict PM-related health beliefs as well as mask-wearing behaviors. As the first to examine self-protective mask-wearing behaviors through the HBM lens, the current study has expanded the applicability of HBM and provides practical insights for health promotion practitioners.

Author Contributions: Conceptualization, J.K. and Y.K.; methodology, J.K.; software, J.K.; validation, J.K. and Y.K.; formal analysis, J.K.; investigation, J.K.; resources, J.K.; data curation, J.K.; 
writing-original draft preparation, J.K.; writing—review and editing, J.K. and Y.K.; visualization, J.K.; supervision, J.K.; project administration, J.K.; funding acquisition, J.K. Both authors have read and agreed to the published version of the manuscript.

Funding: This work was supported by the Ministry of Education of the Republic of Korea and the National Research Foundation of Korea (NRF-2018S1A5A2A03038195).

Institutional Review Board Statement: The study was conducted according to the guidelines of the Declaration of Helsinki and approved by the Institutional Review Board of Kookmin University (KMU-201812-HR-192).

Informed Consent Statement: Informed consent was obtained from all subjects involved in the study.

Data Availability Statement: The data that support the findings of this study are available from the corresponding author, J.K., upon request.

Conflicts of Interest: The authors declare no conflict of interest.

\section{References}

1. World Health Organization. Deaths Linked to Outdoor and Household Air Pollution. Available online: https://www.who.int/ airpollution/infographics / Air-pollution-INFOGRAPHICS-English-2-1200px.jpg?ua=1 (accessed on 6 February 2021).

2. World Health Organization. WHO Releases Country Estimates on Air Pollution Exposure and Health Impact. Available online: https:/ / www.who.int/news/item/27-09-2016-who-releases-country-estimates-on-air-pollution-exposure-and-healthimpact (accessed on 6 February 2021).

3. World Health Organization. Ambient air pollution: Pollutans. Available online: https://www.who.int/airpollution/ambient/ pollutants/en (accessed on 6 February 2021).

4. Environmental Protection Agency. Particulate Matter (PM) Basics. Available online: https://www.epa.gov/pm-pollution/ particulate-matter-pm-basics (accessed on 6 February 2021).

5. Centers for Disease Control and Prevention. Particle Pollution. Available online: https://www.cdc.gov/air/particulate_matter. html (accessed on 6 February 2021).

6. Cohen, A.J.; Brauer, M.; Burnett, R.; Anderson, H.R.; Frostad, J.; Estep, K.; Balakrishnan, K.; Brunekreef, B.; Dandona, L.; Dandona, R. Estimates and 25-year trends of the global burden of disease attributable to ambient air pollution: An analysis of data from the Global Burden of Diseases Study 2015. Lancet 2017, 389, 1907-1918. [CrossRef]

7. OECD. Air Pollution Exposure. Available online: https:/ / data.oecd.org/air/air-pollution-exposure.htm (accessed on 6 February 2021).

8. Ministry of Environment. Special Act on the Reduction and Management of Fine Dust. In Act No. 15718; Ministry of Environment: Seoul, Korea, 2018.

9. National Institute of Environmental Research. Annual Report of Ambient Air Quality. Available online: http://www.airkorea.or. kr/web/detailViewDown?pMENU_NO=125 (accessed on 6 February 2021).

10. Yoo, J. The worst find dust situation continues ... why do not wear masks? Money Today. Available online: https://news.mt.co. $\mathrm{kr} / \mathrm{mtview}$.php?no=2018032616094699655 (accessed on 6 February 2021).

11. Lee, H. How to select a fine dust mask, higher KF numbers indicate greater protection. Health Chosun Website. Available online: https:/ /health.chosun.com/site/data/html_dir/2019/01/14/2019011400988.html (accessed on 6 February 2021).

12. Cherrie, J.W.; Apsley, A.; Cowie, H.; Steinle, S.; Mueller, W.; Lin, C.; Horwell, C.J.; Sleeuwenhoek, A.; Loh, M. Effectiveness of face masks used to protect Beijing residents against particulate air pollution. Occup. Environ. Med. 2018, 75, 446-452. [CrossRef] [PubMed]

13. Zhang, G.-H.; Zhu, Q.-H.; Zhang, L.; Yong, F.; Zhang, Z.; Wang, S.-L.; Wang, Y.; He, L.; Tao, G.-H. High-performance particulate matter including nanoscale particle removal by a self-powered air filter. Nat. Commun. 2020, 11, 1-10. [CrossRef] [PubMed]

14. Kyung, S.Y.; Jeong, S.H. Particulate-matter related respiratory diseases. Tuberc. Respir. Dis. 2020, 83, 116. [CrossRef]

15. Rosenstock, I.M. Historical origins of the health belief model. Health Educ. Monogr. 1974, 2, 328-335. [CrossRef]

16. Painter, J.E.; Borba, C.P.; Hynes, M.; Mays, D.; Glanz, K. The use of theory in health behavior research from 2000 to 2005: A systematic review. Ann. Behav. Med. 2008, 35, 358-362. [CrossRef]

17. Rosenstock, I.M. The health belief model and preventive health behavior. Health Educ. Monogr. 1974, 2, 354-386. [CrossRef]

18. Rosenstock, I.M. What research in motivation suggests for public health. Am. J. Public Health Nations Health 1960, 50, 295-302. [CrossRef] [PubMed]

19. Becker, M.H. The health belief model and sick role behavior. Health Educ. Monogr. 1974, 2, 409-419. [CrossRef]

20. Becker, M.H.; Maiman, L.A.; Kirscht, J.P.; Haefner, D.P.; Drachman, R.H. The Health Belief Model and prediction of dietary compliance: A field experiment. J. Health Soc. Behav. 1977, 18, 348-366. [CrossRef]

21. Champion, V.L.; Skinner, C.S. The health belief model. Health Behav. Health Educ. Theory Res. Pract. 2008, 4, 45-65.

22. Becker, M.H.; Maiman, L.A. Sociobehavioral determinants of compliance with health and medical care recommendations. Med. Care 1975, 13, 10-24. [CrossRef] 
23. Champion, V.L.; Ray, D.W.; Heilman, D.K.; Springston, J.K. A tailored intervention for mammography among low-income African-American women. J. Psychosoc. Oncol. 2000, 18, 1-13. [CrossRef]

24. Mahoney, C.A.; Thombs, D.L.; Ford, O.J. Health belief and self-efficacy models: Their utility in explaining college student condom use. Aids Educ. Prev. 1995, 7, 32-49. [PubMed]

25. Nan, X.; Kim, J. Predicting H1N1 vaccine uptake and H1N1-related health beliefs: The role of individual difference in consideration of future consequences. J. Health Commun. 2014, 19, 376-388. [CrossRef] [PubMed]

26. Kim, J.; Nan, X. Consideration of future consequences and HPV vaccine uptake among young adults. J. Health Commun. 2015, 20, 1033-1040. [CrossRef]

27. Saklofske, D.H.; Austin, E.J.; Rohr, B.A.; Andrews, J.J. Personality, emotional intelligence and exercise. J. Health Psychol. 2007, 12, 937-948. [CrossRef] [PubMed]

28. Kim, J.; Anagondahalli, D. The effects of temporal perspective on college students' energy drink consumption. Health Psychol. 2017, 36, 898. [CrossRef]

29. Schmitz, J.M.; Spiga, R.; Rhoades, H.M.; Fuentes, F.; Grabowski, J. Smoking cessation in women with cardiac risk: A comparative study of two theoretically based therapies. Nicotine Tob. Res. 1999, 1, 87-94. [CrossRef]

30. Becker, M.H. The health belief model and personal health behavior. Health Educ. Monogr. 1974, 2, 324-473. [CrossRef]

31. Janz, N.K.; Becker, M.H. The health belief model: A decade later. Health Educ. Q. 1984, 11, 1-47. [CrossRef]

32. Carpenter, C.J. A meta-analysis of the effectiveness of health belief model variables in predicting behavior. Health Commun. 2010, 25, 661-669. [CrossRef] [PubMed]

33. Harrison, J.A.; Mullen, P.D.; Green, L.W. A meta-analysis of studies of the health belief model with adults. Health Educ. Res. 1992, 7, 107-116. [CrossRef]

34. Lin, P.; Simoni, J.M.; Zemon, V. The health belief model, sexual behaviors, and HIV risk among Taiwanese immigrants. Aids Educ. Prev. 2005, 17, 469-483. [CrossRef] [PubMed]

35. Farquharson, L.; Noble, L.M.; Barker, C.; Behrens, R.H. Health beliefs and communication in the travel clinic consultation as predictors of adherence to malaria chemoprophylaxis. Br. J. Health Psychol. 2004, 9, 201-217. [CrossRef] [PubMed]

36. Gerend, M.A.; Shepherd, M.A.; Shepherd, J.E. The multidimensional nature of perceived barriers: Global versus practical barriers to HPV vaccination. Health Psychol. 2013, 32, 361. [CrossRef]

37. Kim, J. The relationship of health beliefs with information sources and HPV vaccine acceptance among young adults in Korea. Int. J. Environ. Res. Public Health 2018, 15, 673. [CrossRef]

38. Faul, F.; Erdfelder, E.; Lang, A.G.; Buchner, A. G* Power 3: A flexible statistical power analysis program for the social, behavioral, and biomedical sciences. Behav. Res. Methods 2007, 39, 175-191. [CrossRef]

39. Hansstein, F.V.; Echegaray, F. Exploring motivations behind pollution-mask use in a sample of young adults in urban China. Glob. Health 2018, 14, 1-10. [CrossRef] [PubMed]

40. Delli Carpini, M.X. In search of the informed citizen: What Americans know about politics and why it matters. Commun. Rev. 2000, 4, 129-164. [CrossRef]

41. Eveland, W.P., Jr. Interactions and nonlinearity in mass communication: Connecting theory and methodology. Journal. Mass Commun. Q. 1997, 74, 400-416. [CrossRef]

42. Tichenor, P.J.; Donohue, G.A.; Olien, C.N. Mass media flow and differential growth in knowledge. Public Opin. Q. 1970, 34, 159-170. [CrossRef]

43. Kwak, N. Revisiting the knowledge gap hypothesis: Education, motivation, and media use. Commun. Res. 1999, 26, 385-413. [CrossRef]

44. Wong, T. Coronavirus: Why some countries wear face masks and others don't. BBC News Website. Available online: https: / / www.bbc.com/news/world-52015486 (accessed on 6 February 2021). 